\title{
Comparison of Long-Term Postoperative Sequelae in Patients With Tetralogy of Fallot Versus Isolated Pulmonic Stenosis
}

\author{
Michael J. Zdradzinski, BA ${ }^{\mathrm{a}, \mathrm{b}}$, Athar M. Qureshi, MD ${ }^{\mathrm{c}}$, Robert Stewart, MD ${ }^{\mathrm{d}}$, \\ Gosta Pettersson, MD, $\mathrm{PhD}^{\mathrm{d}}$, and Richard A. Krasuski, MD ${ }^{\mathrm{a}, *}$
}

\begin{abstract}
Patients with tetralogy of Fallot (TOF) after complete repair and pulmonic stenosis (PS) after surgical valvotomy often develop significant pulmonic regurgitation (PR) that eventually requires valve replacement. Although criteria exist for the timing of pulmonary valve replacement in TOF, it remains less clear when to intervene in valvotomy patients and whether TOF recommendations can be applied. Our aim was to compare the structural and functional sequelae of valvotomy for PS with complete repair for TOF. We compared the clinical characteristics, electrocardiograms, echocardiograms, cardiac magnetic resonance imaging (MRI), and invasive hemodynamics of 109 adults (34 PS and 75 TOF) newly referred to a congenital heart disease center for evaluation of PR between 2005 and 2012. Both cohorts were similar in terms of baseline demographics and presenting New York Heart Association function class. Valvotomy patients had a slightly greater degree of PR by echocardiogram, although it was similar by cardiac MRI. Electrocardiography QRS width was greater in patients with TOF $(114 \pm 27$ vs $150 \pm 28 \mathrm{~ms}, \mathrm{p}<0.001)$. MRI right ventricular ejection fraction ( $49 \pm 8 \mathrm{vs} 41 \pm 11 \%, \mathrm{p}=0.001)$ and left ventricular ejection fraction $(59 \pm$ 7 vs $52 \pm 10 \%, p=0.002$ ) were lower in patients with TOF. Pacemaker or defibrillator implantation was significantly greater in patients with TOF (3\% vs $23 \%, \mathrm{p}=0.011)$. In conclusion, patients postvalvotomy and complete repair present with similar degrees of PR and severity of symptoms. Biventricular systolic function and electrocardiography QRS width appear less affected, suggesting morphologic changes in TOF and its repair that extend beyond the effects of PR. These findings suggest the need for developing diseasespecific guidelines for patients with PR postvalvotomy. (c) 2014 Elsevier Inc. All rights reserved. (Am J Cardiol 2014;114:300-304)
\end{abstract}

Tetralogy of Fallot (TOF) and isolated pulmonic stenosis (PS) are common congenital disorders that often require early corrective intervention. ${ }^{1-4}$ Traditional corrective surgery for TOF ("complete repair") and surgical valvotomy for PS frequently have resulted in significant pulmonic regurgitation $(\mathrm{PR}) .^{5-9}$ In both populations, the resultant $\mathrm{PR}$ places patients at risk for right ventricular (RV) dysfunction, arrhythmias, and sudden death. ${ }^{10-13}$ Pulmonary valve replacement (PVR) is the gold standard therapeutic option because medical management is often ineffective. ${ }^{14-16}$ The timing of PVR is controversial, with early replacement limited by long-term prosthetic valve degeneration and delayed replacement risking the development of irreversible RV damage ${ }^{17}$ For this reason, the timing of PVR after TOF repair has been well-studied, and specific guidelines exist to

\footnotetext{
${ }^{\mathrm{a} D e p a r t m e n t}$ of Cardiovascular Medicine, The Cleveland Clinic, Cleveland, Ohio; ${ }^{\mathrm{b}}$ Cleveland Clinic Lerner College of Medicine, Case Western Reserve University, Cleveland, Ohio; ${ }^{\mathrm{c}}$ Department of Pediatric Cardiology, The Cleveland Clinic, Cleveland, Ohio; and ${ }^{\mathrm{d}}$ Department of Pediatric and Congenital Heart Surgery, The Cleveland Clinic, Cleveland, Ohio. Manuscript received February 14, 2014; revised manuscript received and accepted April 24, 2014.

This study was supported by the National Heart, Lung, and Blood Institute at the National Institutes of Health (NIH T35 HL082544).

See page 303 for disclosure information.

*Corresponding author: Tel: (216) 445-7433; fax: (216) 445-6163.

E-mail address: krasusr@ccf.org (R.A. Krasuski).
}

determine the appropriate timing of intervention. ${ }^{18-23} \mathrm{Un}$ fortunately, few studies exist to guide the timing of PVR in the PS population. ${ }^{18}$ Many providers, therefore, apply the TOF guidelines to valvotomy patients despite the fundamentally different anatomy, pathophysiology, and surgical corrections of these conditions. To assess whether the two populations are truly comparable, we examined the structural, functional, and symptomatic sequelae of patients with PR resulting from TOF repair and valvotomy referred for initial assessment at an adult congenital heart disease center.

\section{Methods}

In this retrospective, incipient cohort study, we identified 109 patients from the Cleveland Clinic Adult Congenital Heart Disease Database who were newly referred between July 2005 and June 2012 for evaluation of moderate or greater native valve PR (as quantified by echocardiography) related to previous surgical repair of PS or TOF. All patients underwent an electrocardiogram and an echocardiogram at the initial clinic visit, with cardiac magnetic resonance imaging (MRI) and heart catheterization subsequently performed in appropriately selected patients. Patients with left bundle branch block, previous PVR, or those with greater mild RV outflow narrowing evident on imaging were excluded. In addition, those with other major additional cardiac malformations (i.e., double-chambered right ventricle, transposition of great vessels, atrioventricular 
Table 1

Demographic data at presentation

\begin{tabular}{lccr}
\hline Variable & $\begin{array}{c}\text { Pulmonic Stenosis } \\
(\mathrm{n}=34)\end{array}$ & $\begin{array}{c}\text { Tetralogy of Fallot } \\
(\mathrm{n}=75)\end{array}$ & $\mathrm{p}$ Value \\
\hline Age, years & $47.0 \pm 13.5$ & $43.9 \pm 13.3$ & 0.260 \\
Male & $17(50 \%)$ & $43(58 \%)$ & 0.536 \\
Body mass index, $\mathrm{kg} / \mathrm{m}^{2}$ & $28.6 \pm 7.1$ & $27.4 \pm 6.8$ & 0.388 \\
Age at first repair, years & $6.8 \pm 8.5$ & $8.5 \pm 10.3$ & 0.411 \\
Time from repair to & $37.5 \pm 10.5$ & $32.3 \pm 10.6$ & 0.023 \\
$\quad$ presentation, years & & & \\
Shunt & $1(3 \%)$ & $30(40 \%)$ & $<0.001$ \\
Pacer/implantable cardiac & $1(3 \%)$ & $17(23 \%)$ & 0.011 \\
$\quad$ defibrillator & & & \\
New York heart Association & $1.7 \pm 0.7$ & $1.6 \pm 0.6$ & 0.506 \\
$\quad$ functional class & $11(32 \%)$ & $19(25 \%)$ & 0.491 \\
Hypertension & $1(3 \%)$ & $11(15 \%)$ & 0.100 \\
Pulmonary hypertension & $2(6 \%)$ & $4(5 \%)$ & 1.000 \\
Diabetes mellitus & $3(9 \%)$ & $12(16 \%)$ & 0.383 \\
Hyperlipidemia & $8(24 \%)$ & $18(24 \%)$ & 1.000 \\
Smoker & & & \\
\hline
\end{tabular}

Data given as mean $\pm \mathrm{SD}$.

Table 2

EKG and echocardiogram data

\begin{tabular}{|c|c|c|c|}
\hline Variable & $\begin{array}{l}\text { Pulmonic } \\
\text { Stenosis }\end{array}$ & $\begin{array}{l}\text { Tetralogy of } \\
\text { Fallot }\end{array}$ & $\mathrm{p}$ Value \\
\hline PR interval, ms & $177 \pm 32$ & $177 \pm 55$ & 0.946 \\
\hline QRS width, ms & $114 \pm 27$ & $150 \pm 28$ & $<0.001$ \\
\hline QTc, ms & $421 \pm 51$ & $420 \pm 53$ & 0.888 \\
\hline Right atrium volume, $\mathrm{ml}$ & $25.1 \pm 10.6$ & $27.0 \pm 10.6$ & 0.560 \\
\hline Right ventricle volume & $1.5 \pm 1.0$ & $1.5 \pm 1.0$ & 0.761 \\
\hline Right ventricle function ${ }^{\dagger}$ & $1(0,2)$ & $1(0,2)$ & 0.512 \\
\hline Left ventricle diastolic width, $\mathrm{cm}$ & $4.4 \pm 0.5$ & $4.5 \pm 0.8$ & 0.457 \\
\hline Left ventricle systolic width, $\mathrm{cm}$ & $2.9 \pm 0.5$ & $3.1 \pm 0.6$ & 0.289 \\
\hline Left ventricle function ${ }^{\dagger}$ & $0(0,0)$ & $0(0,0)$ & 0.163 \\
\hline Aortic regurgitation ${ }^{*}$ & $0(0,0)$ & $0.5(0,2)$ & 0.021 \\
\hline Pulmonic regurgitation & $3.2 \pm 0.9$ & $2.4 \pm 1.6$ & 0.004 \\
\hline Mitral regurgitation & $0.9 \pm 0.6$ & $0.9 \pm 0.9$ & 0.869 \\
\hline Tricuspid regurgitation & $1.5 \pm 1.0$ & $1.5 \pm 0.9$ & 0.853 \\
\hline Pulmonic gradient, $\mathrm{mm} \mathrm{Hg}$ & $8.2 \pm 3.1$ & $13.9 \pm 8.2$ & 0.007 \\
\hline $\begin{array}{l}\text { Right ventricular systolic pressure, } \\
\mathrm{mm} \mathrm{Hg}\end{array}$ & $35 \pm 13$ & $46 \pm 20$ & 0.007 \\
\hline Left ventricle ejection fraction, $\%$ & $56 \pm 5$ & $54 \pm 8$ & 0.166 \\
\hline
\end{tabular}

Data given as mean $\pm \mathrm{SD}$.

$\mathrm{EKG}=$ electrocardiogram; $\mathrm{PR}=$ pulmonic regurgitation; $\mathrm{QTc}=$ corrected QT interval.

* Data given as median (IQ range).

† Volume/function graded from 0 (normal) to 3 (severely dilated/ decreased).

${ }^{\ddagger}$ Valvular regurgitation graded as 0 (none), 1 (mild) to 4 (severe).

canal type defect or anomalous pulmonary venous return) were excluded. Other cardiac comorbidities, including residual atrial and ventricular septal defects and peripheral pulmonic stenosis, were individually reviewed by a committee of investigators for their contribution to cardiac structure and risk of arrhythmia before possible exclusion. The study was approved by the Institutional Review Board of the Cleveland Clinic.

Data were abstracted from the database and augmented by review of the electronic and paper medical records, which included baseline demographics, cardiac medical and
Table 3

Invasive hemodynamic data

\begin{tabular}{lccc}
\hline Variable & $\begin{array}{c}\text { Pulmonic } \\
\text { Stenosis } \\
(\mathrm{n}=18)\end{array}$ & $\begin{array}{c}\text { Tetralogy } \\
\text { of Fallot } \\
(\mathrm{n}=38)\end{array}$ & $\begin{array}{c}\mathrm{p} \\
\text { Value }\end{array}$ \\
\hline Right atrial mean, mm Hg & $10.1 \pm 5.4$ & $11.4 \pm 6.5$ & 0.487 \\
Systolic pulmonary artery, mm Hg & $35.4 \pm 11.6$ & $42.2 \pm 22.2$ & 0.159 \\
Diastolic pulmonary artery, mm Hg & $12.6 \pm 5.1$ & $13.8 \pm 10.5$ & 0.584 \\
Mean pulmonary artery, mm Hg & $21.0 \pm 5.2$ & $23.9 \pm 14.2$ & 0.348 \\
$\begin{array}{l}\text { Systolic right ventricle, mm Hg } \\
\text { Diastolic right ventricle, }{ }^{*} \mathrm{~mm} \mathrm{Hg}\end{array}$ & $\begin{array}{c}41.2 \pm 12.9 \\
\text { Mean pulmonary capillary wedge } \\
\quad \text { pressure, mm Hg }\end{array}$ & $12.5 \pm 4.3 \pm 20.5$ & 0.102 \\
Fick cardiac index, $1 / \mathrm{min} / \mathrm{m}^{2}$ & $2.4 \pm 0.5$ & $10(6,13.5)$ & 0.767 \\
& & $2.4 \pm 0.4$ & 0.737 \\
\end{tabular}

Data given as mean $\pm \mathrm{SD}$.

* Data given as median (interquartile range).

Table 4

MRI subgroup analysis

\begin{tabular}{|c|c|c|c|}
\hline Variable & $\begin{array}{c}\text { Pulmonic } \\
\text { Stenosis } \\
(\mathrm{n}=24)\end{array}$ & $\begin{array}{l}\text { Tetralogy } \\
\text { of Fallot } \\
(n=39)\end{array}$ & $\begin{array}{c}\mathrm{p} \\
\text { Value }\end{array}$ \\
\hline Age, years & $45.9 \pm 13.3$ & $46.2 \pm 11.7$ & 0.304 \\
\hline Male & $11(46 \%)$ & $23(59 \%)$ & 0.435 \\
\hline Body mass index, $\mathrm{kg} / \mathrm{m}^{2}$ & $27.5 \pm 6.3$ & $27.1 \pm 6.3$ & 0.783 \\
\hline Time from surgery to MRI, years & $36 \pm 11$ & $32 \pm 9$ & 0.152 \\
\hline Shunt & $4 \%$ & $46 \%$ & $<0.001$ \\
\hline $\begin{array}{l}\text { New York Heart Association } \\
\text { class }\end{array}$ & $1.6 \pm 0.6$ & $1.5 \pm 0.6$ & 0.786 \\
\hline Body surface area, $\mathrm{m}^{2}$ & $1.96 \pm 0.28$ & $1.91 \pm 0.24$ & 0.489 \\
\hline $\begin{array}{l}\text { Right ventricular end-diastolic } \\
\text { volume, } \mathrm{ml}\end{array}$ & $267.1 \pm 77.7$ & $256.3 \pm 112.0$ & 0.691 \\
\hline $\begin{array}{l}\text { Right ventricular end-diastolic } \\
\text { volume indexed, } \mathrm{ml} / \mathrm{m}^{2}\end{array}$ & $147.9 \pm 58.8$ & $139.2 \pm 61.7$ & 0.592 \\
\hline $\begin{array}{l}\text { Right ventricular end-systolic } \\
\text { volume, } \mathrm{ml}\end{array}$ & $134.5 \pm 52.7$ & $151.8 \pm 97.0$ & 0.394 \\
\hline $\begin{array}{l}\text { Right ventricular end-systolic } \\
\text { volume indexed, } \mathrm{ml} / \mathrm{m}^{2}\end{array}$ & $73.3 \pm 31.2$ & $82.5 \pm 49.7$ & 0.389 \\
\hline $\begin{array}{l}\text { Right ventricular ejection } \\
\text { fraction, } \%\end{array}$ & $49.1 \pm 7.7$ & $40.8 \pm 11.0$ & 0.001 \\
\hline $\begin{array}{l}\text { Left ventricular end-diastolic } \\
\text { volume, } \mathrm{ml}\end{array}$ & $150.5 \pm 34.4$ & $158.1 \pm 48.1$ & 0.584 \\
\hline $\begin{array}{l}\text { Left ventricular end-diastolic } \\
\text { volume index, } \mathrm{ml} / \mathrm{m}^{2}\end{array}$ & $79.3 \pm 14.8$ & $83.3 \pm 24.6$ & 0.466 \\
\hline $\begin{array}{l}\text { Left ventricular end-systolic } \\
\text { volume, } \mathrm{ml}\end{array}$ & $61.8 \pm 15.7$ & $78.4 \pm 36.3$ & 0.028 \\
\hline $\begin{array}{l}\text { Left ventricular end-systolic } \\
\text { volume index, } \mathrm{ml} / \mathrm{m}^{2}\end{array}$ & $31.7 \pm 7.9$ & $41.3 \pm 19.0$ & 0.015 \\
\hline $\begin{array}{l}\text { Left ventricular ejection } \\
\text { fraction, } \%\end{array}$ & $59.3 \pm 7.1$ & $52.1 \pm 9.6$ & 0.002 \\
\hline Pulmonic regurgitation, $\%$ & $32.3 \pm 18.9$ & $37.3 \pm 21.6$ & 0.394 \\
\hline Aortic regurgitation, $\%$ & $2.8 \pm 6.4$ & $4.3 \pm 4.5$ & 0.341 \\
\hline Root diameter, cm & $3.1 \pm 0.3$ & $4.0 \pm 0.6$ & $<0.001$ \\
\hline Ascending diameter, $\mathrm{cm}$ & $3.0 \pm 0.6$ & $3.6 \pm 0.8$ & 0.054 \\
\hline
\end{tabular}

Data given as mean $\pm \mathrm{SD}$; Values indexed by body surface area. MRI = magnetic resonance imaging.

surgical history, comorbidities, symptom severity as measured by New York Heart Association functional class, electrocardiographic and imaging data, and hemodynamic tracings. 
Electrocardiogram analysis was limited to nonpaced tracings. Blinded, qualitative assessments of cardiac chamber sizes by echocardiography were quantified as: $0=$ normal, $1=$ mild, $2=$ moderate, $3=$ moderate to severe, and $4=$ severe enlargement. Similarly, RV function by echocardiogram was quantified as: $0=$ normal, $1=$ mild, $2=$ moderate, 3 = moderate to severe, and $4=$ severe dysfunction. Cardiac catheterization data included right heart pressures, cardiac index calculated by Fick method, and the presence and severity of coronary artery disease. Cardiac MRI data included chamber sizes and function, quantified valvular regurgitation, and aortic dimensions. Volumetric data by MRI was indexed using body surface area.

Comparisons of dichotomous variables between groups were performed using the Pearson chi-square test, Fisher's exact test, or Wilcoxon rank-sum test where appropriate. Comparisons of continuous variables were performed using two-sided t-tests. For all tests, a $\mathrm{p}<0.05$ was considered statistically significant. Data analyses were performed using JMP Pro software version 9.0.0 (SAS Institute Inc., Cary, North Carolina).

\section{Results}

A total of 109 patients (34 PS valvotomy and 75 TOF complete repair) were included in the final analysis (Table 1). Basic demographic data, including age, gender, and body mass index, were similar between groups. There was no difference in mean age at corrective surgery. Patients with PS presented to the Adult Congenital Heart Disease Center an average of $37.5 \pm 10.5$ years after surgery compared with 32.3 \pm 10.6 years in patients with TOF $(\mathrm{p}=0.023)$. Not surprisingly, because of anatomic limitations, patients with repaired TOF were significantly more likely to have required palliative shunting and eventual placement of a pacemaker or cardiac defibrillator. Cardiovascular and noncardiovascular comorbidities were otherwise similar. At presentation, the PS group reported a greater prevalence of chest pain $(29 \%$ vs $12 \%, \mathrm{p}=$ $0.026)$ and shortness of breath at rest $(32 \%$ vs $15 \%, \mathrm{p}=$ 0.033). All other symptoms-including fatigue, cyanosis, orthopnea, palpitations, dyspnea on exertion, home oxygen supplementation and edema-were similar in prevalence between the two groups. Severity of symptoms at presentation also was similar as determined by New York Heart Association function class. Complete operative records were available for $23 \%$ of the cohort. Of the TOF subset, $33 \%$ of the repairs included known use of a transannular patch.

Nonpaced electrocardiographic data were obtained from 95 patients (31 valvotomy and 64 complete repair). PR and corrected QT intervals were similar in both groups (Table 2). QRS duration, however, was significantly greater in the TOF group.

Echocardiographically assessed RV size (mildly to moderately enlarged) and function (mildly decreased) was similar in the 2 groups (Table 2). PR, assessed qualitatively, was slightly more severe in the postvalvotomy group, whereas aortic regurgitation was worse in TOF. RV systolic pressure and pulmonic outflow gradient were both slightly greater in the TOF cohort.

Complete cardiac catheterization data were available in 56 patients (18 PS and 38 TOF). These data demonstrated similar hemodynamics, including right atrial pressure, pulmonary artery pressure, and cardiac indexes in both groups (Table 3).

A total of 63 patients (24 PS and 39 TOF) had complete and technically adequate cardiac MRI data (mean $2.2 \pm$ 2.7 months from the initial evaluation; Table 4). To ensure similarity of this selected cohort to the entire study population, baseline demographic data were recompared, with no significant differences observed. As with the entire cohort, patients with TOF in this subgroup were substantially more likely to have a pervious history of palliative shunt placement.

Both groups experienced similar degrees of RV dilation, including indexed RV end-diastolic and end-systolic volumes. RV ejection fraction was significantly greater postvalvotomy. Although left ventricular (LV) volumes fell within normal range for patients with PS, they were mildly increased in the TOF group, and the LV ejection fraction was also lower in the TOF group.

Flow measurements demonstrated similar degrees of pulmonic and aortic regurgitation in both groups. There was no significant difference in pulmonic valve regurgitant fraction, which was increased in both groups. Although aortic regurgitant fractions were similarly small in both groups, aortas were larger in patients with TOF, including larger root and mid-ascending aorta diameters.

\section{Discussion}

In a similarly symptomatic cohort of patients with PS after valvotomy and TOF after complete repair, we found that structural and functional sequelae were significantly more evident with TOF. Although valvotomy patients appeared to have a greater degree of PR by echocardiography, MRI quantification was similar. This finding likely reflects the greater accuracy of cardiac MRI in the quantification of PR. Alternatively, the exclusion of patients with pacemaker and defibrillators (still considered a contraindication to MRI scanning) may have altered the TOF cohort. Comparison of the full cohort and those undergoing MRI scanning, however, did not suggest any major differences. Furthermore, it should be suspected that patients with previously placed defibrillators would have wider QRS durations, more dilated right ventricles, and thus greater PR. Excluding these patients would therefore be expected to reduce the degree of $\mathrm{PR}$ observed in the TOF cohort and widen the observed difference, contrary to what was seen.

RV volumes were similarly increased in both groups, although the RV ejection fraction was considerably lower in patients with TOF. This measure is more sensitive to changes, and it reflects the effect of slightly smaller enddiastolic volumes and larger end-systolic volumes in TOF. LV end-systolic volume was larger and ejection fraction lower in patients with TOF. LV dysfunction recently has been characterized in the TOF population. ${ }^{24}$ It appears from our data that PS patients are spared this effect and suggests a pathologic effect in TOF beyond longstanding right-sided volume overload from PR. It is important to note that the decrease in $\mathrm{LV}$ function was seen in a cohort of patients with TOF who did not have implantable devices, thus excluding the potentially detrimental effect of pacing, which 
previously has been reported in other cohorts of patients. Also important to note is that invasive hemodynamics suggest no difference in pulmonary capillary wedge pressure, suggesting a smaller role of LV involvement on the presence of symptoms in these patient populations.

Aortic sizes tended to be larger in patients with TOF. This finding is not surprising because TOF is a conotruncal abnormality with aortic override being a major component. Aortic dissection has been reported in patients with TOF; fortunately, it does not appear that the PS population is prone to this problem.

Sudden death is a well-described phenomenon in patients with congenital heart disease, particularly in TOF, and risk in the latter appears to be mitigated by RV size and function. ${ }^{24}$ QRS complex width has been proposed as an effective marker for predicting future risk in TOF and a cutoff of $180 \mathrm{~ms}$ has been proposed for defining patients at particularly high risk. ${ }^{10,25}$ Many clinicians regularly track this value to help decide when to intervene operatively for PR. Interestingly, QRS width was considerably less in patients with PS and only mildly abnormal in these patients despite similarly, significantly enlarged right ventricles. Complete repair in TOF is known to produce right bundle branch block, and our data suggest that physicians should ideally not apply the cut-offs derived from TOF to the PS population. Further studies should investigate sudden death risk in the postvalvotomy population and whether a lower cutpoint or change in QRS width over time is a helpful screening tool.

Current guidelines and indicators for PVR in patients with TOF include criteria for RV size, QRS width, and symptomatic impairment. $^{10,18}$ This study suggests that postvalvotomy patients with PR become symptomatic despite fewer structural changes and functional deficits than do patients with TOF. Therefore, the guidelines developed for PVR in the TOF population do not appear to apply to the postvalvotomy population.

This study is limited by the very selective nature of the patient cohort. All patients were referred to an adult congenital heart disease center based on the presence of PR and/or symptoms of heart failure. As such, we are capturing patients who have developed complications or are otherwise unable to be managed by their general cardiologist. Therefore, one cannot be certain that these findings apply to all patients with PS and previous valvotomy or tetralogy with prior complete repair. Nonetheless, it is a comparison that has not been previously made, and its findings have the potential to change clinical practice if confirmed in other populations. Because of the retrospective nature of data collection, the details of previous surgeries were not always available. In such cases, the patients were the sole source of clinical information, a common situation in adults with congenital heart disease. We also did not attempt to examine the impact of valvular interventions in this patient population. Future studies should aim to determine the effect of pre-PVR structure and function on the functional, structural, and symptomatic improvement after valve replacement in the postvalvotomy population. This would further facilitate the development of population-specific guidelines.

\section{Disclosures}

The authors have no conflicts of interest to disclose.

1. Bashore TM. Adult congenital heart disease: right ventricular outflow tract lesions. Circulation 2007:115:1933-1947.

2. Jassal DS, Thakrar A, Schaffer SA, Fang T, Kirkpatrick I, Tam JW, Kashour T. Percutaneous balloon valvuloplasty for pulmonic stenosis: the role of multimodality imaging. Echocardiography 2008;25: $231-235$.

3. Fitzgerald KP, Lim MJ. The pulmonary valve. Cardiol Clin 2011;29: 223-227.

4. Laks H, Plunkett MD. Right ventricular outflow tract obstruction with intact ventricular septum. In: Gardner T, Spray T, eds. Operative Cardiac Surgery. 5th ed. New York: Oxford University Press, 2004: $721-724$.

5. Erdem S, Ozbarlas N, Küçükosmanoğlu O, Poyrazoğlu H, Salih OK. Mid-term results of patients following total surgical correction of tetralogy of Fallot. Turk J Pediatr 2012;54:393-402.

6. Bautista-Hernandez V, Cardenas I, Martinez-Bendayan I, Loyola H, Rueda F, Portela F. Valve-sparing tetralogy of Fallot repair with intraoperative dilation of the pulmonary valve. Pediatr Cardiol 2013;34:918-923.

7. Carvalho JS, Shinebourne EA, Busst C, Rigby ML, Redington AN. Exercise capacity after complete repair of tetralogy of Fallot: deleterious effects of residual pulmonary regurgitation. Br Heart J 1992;67: 470-473.

8. Polansky DB, Clark EB, Doty DB. Pulmonary stenosis in infants and young children. Ann Thorac Surg 1985;39:159-164.

9. Kirklin JW, Blackstone EH, Pacifico AD, Kirklin JK, Bargeron LM. Risk factors for early and late failure after repair of tetralogy of Fallot, and their neutralization. Thorac Cardiovasc Surg 1984;32:208-214.

10. Gatzoulis MA, Balaji S, Webber SA, Siu SC, Hokanson JS, Poile C, Rosenthal M, Nakazawa M, Moller JH, Gillette PC, Webb GD, Redington AN. Risk factors for arrhythmia and sudden cardiac death late after repair of tetralogy of Fallot: a multicentre study. Lancet 2000;356: 975-981.

11. Shimazaki Y, Blackstone EH, Kirklin JW. The natural history of isolated congenital pulmonary valve incompetence: surgical implications. Thorac Cardiovasc Surg 1984;32:257-259.

12. Hill G. Repair and follow-up of Tetralogy of Fallot with pulmonary stenosis. Congenit Heart Dis 2013;8:174-177.

13. Yoo BW, Park HK. Pulmonary stenosis and pulmonary regurgitation: both ends of the spectrum in residual hemodynamic impairment after tetralogy of Fallot repair. Korean J Pediatr 2013;56:235-241.

14. Kogon B, Plattner C, Kirshbom P, Kanter K, Leong T, Lyle T, Jennings S, McConnell M, Book W. Risk factors for early pulmonary valve replacement after valve disruption in congenital pulmonary stenosis and tetralogy of Fallot. J Thorac Cardiovasc Surg 2009;138: $103-108$

15. Karagoz T, Asoh K, Hickey E, Chaturvedi R, Lee K-J, Nykanen D, Benson L. Balloon dilation of pulmonary valve stenosis in infants less than 3 kg: A 20-year experience. Catheter Cardiovasc Interv 2009;74: $753-761$.

16. Kogon B, Patel M, Leong T, McConnell M, Book W. Management of moderate functional tricuspid valve regurgitation at the time of pulmonary valve replacement: Is concomitant tricuspid valve repair necessary? Pediatr Cardiol 2010;31:843-848.

17. Lurz P, Bonhoeffer P, Taylor AM. Percutaneous pulmonary valve implantation: an update. Expert Rev Cardiovasc Ther 2009;7: $823-833$

18. Warnes CA, Williams RG, Bashore TM, Child JS, Connolly HM, Dearani JA, del Nido P, Fasules JW, Graham TP Jr, Hijazi ZM, Hunt SA, King ME, Landzberg MJ, Miner PD, Radford MJ, Walsh EP, Webb GD. ACC/AHA 2008 guidelines for the management of adults with congenital heart disease: a report of the American College of Cardiology/American Heart Association Task Force on practice guidelines. Circulation 2008;118:e714-e833.

19. Therrien J, Provost Y, Merchant N, Williams W, Colman J, Webb G. Optimal timing for pulmonary valve replacement in adults after tetralogy of Fallot repair. Am J Cardiol 2005;95:779-782.

20. Oosterhof T, van Straten A, Vliegen HW, Meijboom FJ, van Dijk APJ, Spijkerboer AM, Bouma BJ, Zwinderman AH, Hazekamp 
MG, de Roos A, Mulder BJM. Preoperative thresholds for pulmonary valve replacement in patients with corrected tetralogy of Fallot using cardiovascular magnetic resonance. Circulation 2007:116:545-551.

21. Ammash NM, Dearani JA, Burkhart HM, Connolly HM. Pulmonary regurgitation after tetralogy of Fallot repair: clinical features, sequelae, and timing of pulmonary valve replacement. Congenit Heart Dis 2007:2:386-403.

22. Piazza L, Chessa M, Giamberti A, Bussadori CM, Butera G, Negura DG, Micheletti A, Callus E, Carminati M. Timing of pulmonary valve replacement after tetralogy of Fallot repair. Expert Rev Cardiovasc Ther 2012;10:917-923.
23. Geva T. Indications and timing of pulmonary valve replacement after tetralogy of Fallot repair. Semin Thorac Cardiovasc Surg Pediatr Card Surg Аппи 2006:11-22.

24. Broberg CS, Aboulhosn J, Mongeon F-P, Kay J, Valente AM, Khairy P, Earing MG, Opotowsky AR, Lui G, Gersony DR, Cook S, Ting JG, Webb G, Gurvitz MZ. Alliance for Adult Research in Congenital Cardiology (AARCC). Prevalence of left ventricular systolic dysfunction in adults with repaired tetralogy of Fallot. Am J Cardiol 2011;107:1215-1220.

25. Koyak Z, Harris L, de Groot JR, Silversides CK, Oechslin EN, Bouma BJ, Budts W, Zwinderman AH, Van Gelder IC, Mulder BJM. Sudden cardiac death in adult congenital heart disease. Circulation 2012;126: 1944-1954. 